\title{
Article
}

\section{Properties of Green Mortar Containing Granite Sawmill}

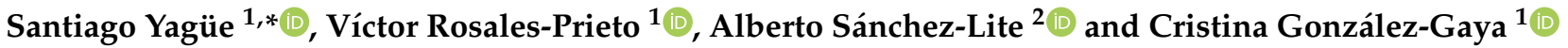 \\ 1 Department of Construction and Manufacturing Engineering, ETSII, National Distance Education \\ University (UNED), C/Juan del Rosal 12, 28040 Madrid, Spain; victor.rosales@ind.uned.es (V.R.-P.); \\ cggaya@ind.uned.es (C.G.-G.) \\ 2 Department of Materials Science and Metallurgical Engineering, Graphic Expression in Engineering, \\ Cartographic Engineering, Geodesy and Photogrammetry, Mechanical Engineering and Manufacturing \\ Engineering, School of Industrial Engineering, Universidad de Valladolid, $\mathrm{P}^{\circ}$ del Cauce 59, \\ 47011 Valladolid, Spain; asanchez@eii.uva.es \\ * Correspondence: syague14@alumno.uned.es
}

Citation: Yagüe, S.; Rosales-Prieto, V.; Sánchez-Lite, A.; González-Gaya, C. Properties of Green Mortar Containing Granite Sawmill. Appl. Sci. 2021, 11, 2136. https://doi.org/ 10.3390/app11052136

Academic Editor: Auxi Barbudo

Received: 31 January 2021

Accepted: 24 February 2021

Published: 28 February 2021

Publisher's Note: MDPI stays neutral with regard to jurisdictional claims in published maps and institutional affiliations.

Copyright: (c) 2021 by the authors. Licensee MDPI, Basel, Switzerland. This article is an open access article distributed under the terms and conditions of the Creative Commons Attribution (CC BY) license (https:/ / creativecommons.org/licenses/by/ $4.0 /)$.

\begin{abstract}
The cement industry is one of the world's largest $\mathrm{CO}_{2}$ emitters. The need to minimize these emissions, and assimilate by substitution and different types of waste, are challenges faced in the European Union. The use of granite sawmill from the ornamental stone industry allows for the manufacturing of pozzolanic cements, in which $10 \%$ and $20 \%$ of ordinary Portland cement (OPC) has been replaced by waste. In the present paper, properties of cements and mortars have been tested (when fresh and once set), such as workability, setting, retraction, mechanical resistance to bending and compression, elastic modulus to compression, creep, retraction, and durability. In all cases and substitution proportions, the results have been as satisfactory as those achieved with OPC, even better, allowing a second life to the waste, and participating in the principles of the circular economy. Bot substitutions are very resistant and have great durability for the gelifraction processes from the new green cements. Using this waste-granite sawmill-its volume is minimized and transfer to a landfill is avoided.
\end{abstract}

Keywords: waste; granite saw dust; pozzolanic reaction; pore size; recycling; gelifraction

\section{Introduction}

Energy expenditure for cement production is increasing [1], although the cement industry tries to produce sustainable cement, participate in the circular economy, and conserve natural heritage, and biodiversity. In Europe, this industry depends, largely, on the supply of raw materials that, in some cases, must be imported, in addition to the energy expenditure for their production and the consequent $\mathrm{CO}_{2}$ emissions [2]. However, the energy demand in clinker production has been reduced, using alternative fuels [3] and recycled materials [4], from a large number of products at the end of their useful lives; they do not enter into viable cycle recovery, leading to a loss of secondary raw materials and, consequently, a negative impact on the environment.

Although cement production initially focused on ordinary Portland cement (OPC), a fraction of this cement was replaced by supplementary cementitious materials from different sources: paper sludge [5], bamboo leaf ash [6], paper sludge and fly ash [7], drinking-water treatment waste [8], calcination of biomass [9], agricultural products [10], coal-mining waste [11], sugar cane bagasse ash [12], palm oil fuel ash [13], rice husk ash [14], coal-mining tailings [15], and others. In the future, all cements will need to be based on materials that are globally available in sufficient quantities. $\mathrm{CaO}, \mathrm{SiO}_{2}, \mathrm{Fe}_{2} \mathrm{O}_{3}$, and $\mathrm{Al}_{2} \mathrm{O}_{3}$, which are considered key materials in this regard [16].

Currently, it is about reusing resource-efficient construction materials, considering the volume of construction and demolition waste $(C \& D W)$ volume generated in the European Union (EU), and the impact of cement-based materials, along with the development of new ecocements and the incorporation of greater quantities of secondary raw materials under 
the standards of their life cycles. C\&DW are of particular relevance in the current context of the European sustainability strategy, because their volume reaches one of the highest waste rates in the EU. The management of this waste has become one of the most urgent needs of modern society, which requires specific actions: the minimization and prevention of the generation of waste, and the promotion of its recovery as a secondary raw material. Moreover, $54 \%$ of $\mathrm{C} \& D W$ are deposited in landfills in the EU, generating significant environmental impacts (loss of incorporated energy, $\mathrm{CO}_{2}$ emissions, and soil pollution).

The most common material in the construction sector is concrete and its composition based on aggregates, binders, water, and chemical additives allows the total or partial replacement of natural aggregates or clinker by recycled aggregates and supplementary cementitious materials, i.e., as waste. This option is one of the most commonly used to achieve a sustainable environment through resource-efficient cement-based construction products.

Currently, waste related to the quarrying and granite-cutting industry is used (it is included in the European Waste Catalog (EWC) and its listing (EWL) as 010413, nonhazardous waste). Ramos et al. [17] have considered in these residues that, if they are ground with enough fineness, the properties of the cement mixture improve. The aforementioned residues generate a denser matrix that reduces the expansion of the mortar with substitution by up to $38 \%$ when compared to Portland cement. Furthermore, the resistance to chlorides is improved, almost $70 \%$, without changing properties, such as workability and resistance [18]. With the same waste, and studying the microstructure of the aggregates generated by adding them to cement, these wastes are investigated by Pacheco Torgal and Castro-Gomes [19] and Ostrowski et al. [20].

Kumar Sharma et al. [21] have shown that the substitution in cement of an aliquot by polished granite residues decreases the compressive and bending strength of the mortar, but provides better results in the absorption of water, abrasion, and permeability. Kumar Gupta and Kumar Vyas [22] consider it advantageous to use the waste generated by the cutting and finishing of granite blocks as a replacement in mortars, providing better results than mortars without replacement [23-25]. The present paper includes the study of the mechanical properties that help to interpret the results obtained by the substitution of $10 \%$ and $20 \%$ waste of granite cutting in OPC, whose mixtures have previously been characterized by XRD, SEM/EDX, with satisfactory results, in terms of structure and pozzolanicity. Properties, such as consistency, setting, shrinkage, volumetric stability, flexural and compressive strength, porosity, and durability in gelifraction processes will now be studied.

\section{Materials and Methodology}

\subsection{Materials}

Three samples have been studied. The P sample corresponds to a residue from the cutting of granite blocks with water as a lubricant. This water is removed by evaporation. The PR-1 sample is a residue of the dry working of gray granite, and the PR-2 sample is similar to the previous one, only that the starting material is the so-called blond granite. The difference between both samples is the biotite concentration A commercial ordinary Portland cement (OPC) type CEM I $42.5 \mathrm{R}$ is used for the substitutions, and the sand meets the specifications of CEN EN 196-1 standard [26].

\subsection{Methodology}

For workability, setting times have been established according to UNE-EN 196-3 standard [27]. The particle size was determined by laser diffraction spectrometry (LDS) in a range of $0.1 \mu \mathrm{m}$ to $1750 \mu \mathrm{m}$ (SYPATEC HELOS 12 LA spectrometer).

Properties in a hardened state have been determined, such as flexural [28] and compressive strength [29], longitudinal deformation modulus [30], standard creep [31], shrinkage [32], and durability [33]. Durability was evaluated from the elasticity modulus variation, by ultrasound, as well as the change in weight. For these measurements, there has been used a climatic chamber capable of guaranteeing continuous freeze/thaw cycles at a 
temperature between $-20^{\circ} \mathrm{C}$ and $+15^{\circ} \mathrm{C}$ [34]. The speed of the ultrasound was measured using a TICI-PROCEQ ultrasound with a frequency of $54 \mathrm{~Hz}$.

Since the mechanical resistance of cement-based materials is closely related to the microporosity of the cementitious matrix [35]. They were determined by means of a computed tomography (CT-Scanner XT-H-160 from NIKON with Target of W, $0.375 \mathrm{~mm} \mathrm{Cu}$ filter with $708 \mathrm{~ms}$ times per frame, with a total of 4 frames, and number of projections from 1100 to $155 \mathrm{kV}$ and $57 \mu \mathrm{A}$ ) to obtain images of sections in the different internal structures.

The analysis for the identification of solid phases has been carried out by XRD in an Xray diffractometer model SIEMENS D-5000. Identification and quantification is performed the Match v.3 program and Rietveld Full Prof software (Match!) with the Inorganic Crystal Structure Database (ICSD) and the Crystallography Open Database (COD) [36], with rutile as the internal standard in the samples. The equipment used for SEM/EDX analysis was a PHILIPS model XL scanning electron microscope with tungsten source.

\section{Results and Discussion}

\subsection{Natural Samples}

Granite sawdust is a material whose main components are quartz, feldspars, and phyllosilicates that provide OPC rich in alkalis, with a high concentration of $\mathrm{Si}$ and $\mathrm{Al}$, which helps to improve the properties of cement, such as workability, generating ecological pozzolanic cement. These new "green" cements enter the cement manufacturing cycle and the waste recycling cycle, replacing current raw materials.

All samples were of similar mineralogical composition, with varying contents of albite and orthoclase, as well as quartz, biotite, chlorite, and hematite. The PR-2 sample lacked kaolinite and had a low concentration of biotite. The PR-1 sample had the highest content of amorphous material (10\%) [37].

\subsection{Properties in Fresh Condition}

Substitutions of 10 and $20 \%$ of granite residue, by weight, have been prepared in initial OPC, according to UNE EN 197-1 [28].

The two systems studied corresponded to $10 \%$ and $20 \%$ waste substitutions in the initial OPC, and monitoring of the species that appeared with the additions at 1, 7, 28, 90, 180 , and 360 days of curing, compared to the OPC anhydrous in the same curing time.

The XRD patterns of the $10 \%$ and $20 \%$ substitution granite waste samples showed calcite, alite, belite, bassanite, ferritic phase (C3AF), tricalcium aluminate, portlandite, ettringite, and tetracalcium aluminate hydrate $(\mathrm{C} 4 \mathrm{AF})$.

\subsubsection{Consistency}

The consistency of cement mortars is an indirect measure of workability. This property indicates the ability to flow. The mix test was carried out with the reference sand and the cements with the proposed substitutions, spreading the mass on the shaking table. The results on the cement mortars consistency are found in Table 1. The mean values corresponding to three determinations of consistency are provided. In addition, the loss of fluidity of cements with the addition is detailed, in relation to the standard cement (OPC).

Table 1. Consistency of mortars made with different waste additions. (CPO = Cement Portland Ordinary).

\begin{tabular}{ccc}
\hline Mortar & Medium Consistency $(\mathbf{m m})$ & Loss of Fluidity (\%) \\
\hline CPO-10\% P & 142.6 & 18.47 \\
CPO-20\% P & 136.8 & 35.17 \\
CPO-10\% PR1 & 140.1 & 20.11 \\
CPO-20\% PR1 & 137.2 & 36.22 \\
CPO-10\% PR2 & 140.4 & 19.15 \\
CPO-20\% PR2 & 138.4 & 35.78 \\
\hline
\end{tabular}


A decrease is detected in the measurement of the diameters of the extended mass (medium consistency), when the percentage of substitution increases from $10 \%$ to $20 \%$. The loss of fluidity has a linear trend as the percentage of addition waste increases (from 10\% to $20 \%$ ). The consistencies are very similar for all samples, as well as the loss of fluidity as seen in Figure 1.

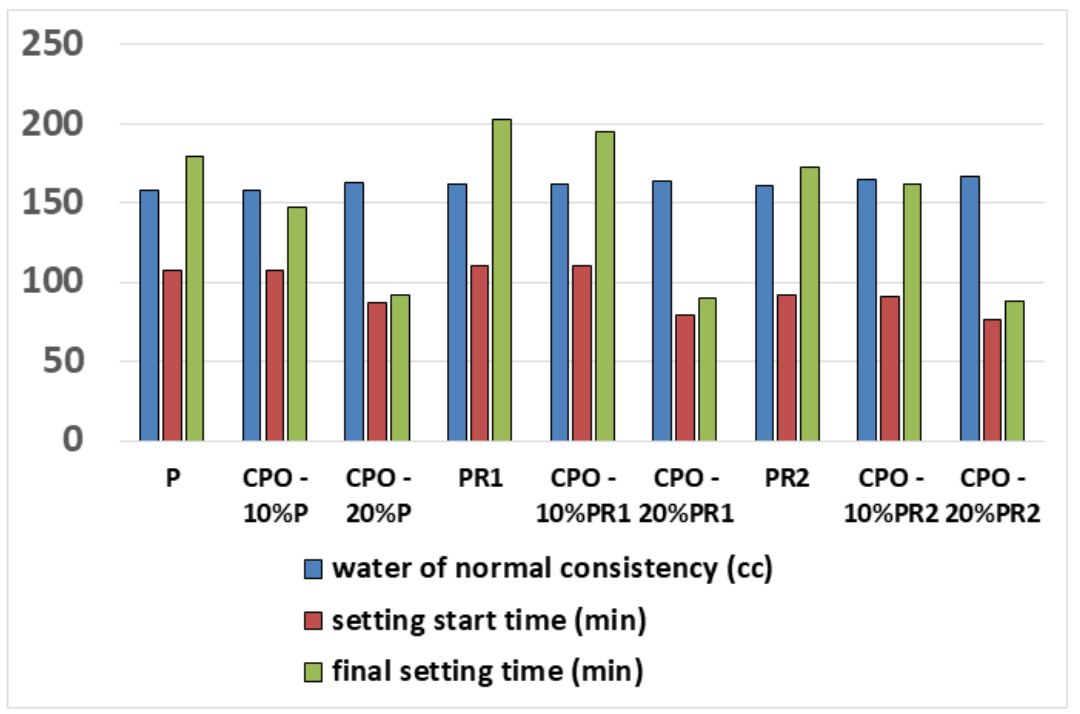

Figure 1. Setting related parameters for each mixture.

Studies on admixture cements using metakaolin [38] show that the resulting mixtures increase the water demand necessary to maintain their workability. The replacement of metakaolin by low cement content ( $5 \%$ by mass) practically does not affect the fluidity of the paste. However, with higher percentages of substitution (greater than 10\%), reducing or superplasticizing products in the addition of water are usually necessary to guarantee workability.

\subsubsection{Setting}

The test was carried out on cement pastes with substitutions that have been proposed and the setting time was determined with the Vicat needle. Waste added to the cement paste generated a parabolic tendency of increase in the water demand for a normal consistency. The higher demand for water corresponds to the higher specific surface area and the finer size distribution in some wastes that are added to the cement, which hinders the fluidity of the cement paste. As shown in Figure 1, more water is required to wet the entire surface of the cement, as it is larger.

The smallest setting times correspond to the larger waste substitutions in the cement. The justification for this process may be related to the particle size: the finer particles will serve as crystallization nuclei that help in hydrated phase formation [39].

The reaction products obtained in the waste/cement system, in all cases and additions studied, are, above all, layered double hydroxide (LDH) compounds, whose concentrations increase with setting time, in addition to portlandite and amorphous material. LDH compounds presence reduces the carbonation of the cement. All of these products enhance their formation when the substitution is $20 \%$ waste and, therefore, they are directly linked to the setting time. In an inverse relationship: higher concentration of reaction products, shorter setting time [40].

\subsubsection{Shrinkage}

The fresh shrinkage test was performed on cement mortars, using the standard sand indicated in the materials and with the substitutions of 10 and $20 \%$ of OPC cement. The dimensions of the molds used were $75 \times 75 \times 300 \mathrm{~mm}$ in which the references were placed 
on the fresh dough. Using the visual method of measure of the shrinkage of the paste, the longitudinal shrinkage was calculated. The shrinkage measurements presented in Figure 2 have been made on the PR-1 sample. Shrinkage increases with exposure time. In all cases, the OPC pattern is the one that most retracts and, on the other hand, the $20 \%$ waste substitution is the one that reaches the lowest values. In the early stages, there is a significant difference between two additions, but with the exposure time, the results of both are practically the same; in any case, they retract less than standard cement.

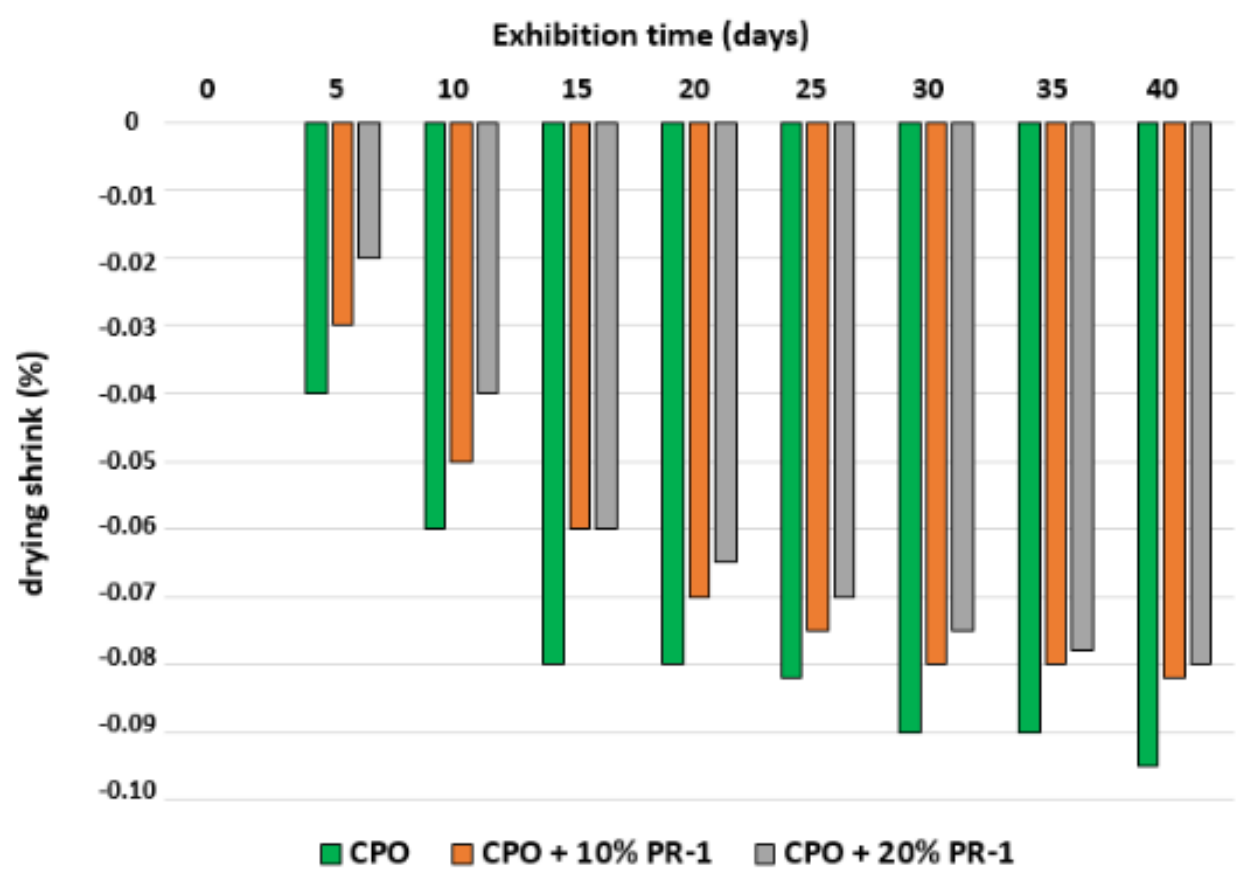

Figure 2. Variation of drying shrinkage in PR-1 sample.

The result is consistent with that obtained by Ózgür Bezgin [41] in materials exposed to different levels of relative humidity, and with $30 \%$ and $50 \%$ addition. In general, it can be said that the shrinkage increases with decreasing humidity.

\subsubsection{Volumetric Stability}

The volume stability test was carried out on cement pastes by measuring the volumetric expansion of the paste of normal consistency, once the Le Chatelier molds had been filled, according to UNE-EN 196-3 [27]. The values obtained in the different measurements are provided in Table 2.

Table 2. Laboratory measurements to determine volume expansivity.

\begin{tabular}{cccc}
\hline Mortar & First Reading $(\mathbf{m m})$ & Second Reading $(\mathbf{m m})$ & Third Reading $(\mathbf{m m})$ \\
\hline $10 \%$ P $+90 \%$ CPO & 0.90 & 1.15 & 1.42 \\
20\% P + 80\% CPO & 1.00 & 1.30 & 1.50 \\
$10 \%$ PR-1 + 90\% CPO & 0.88 & 1.10 & 1.45 \\
$20 \%$ PR-1 + 80\% CPO & 1.10 & 1.40 & 1.60 \\
$10 \%$ PR-2 + 90\% CPO & 0.90 & 1.10 & 1.40 \\
$20 \%$ PR-2 + 80\% CPO & 0.95 & 1.20 & 1.45 \\
\hline
\end{tabular}

By the partial readings, a slight increase in the expansion of the pastes is detected in the $10 \%$ waste substitution; the explanation may be due to the incorporation of free lime linked to the decomposition of calcite and ettringite formation [42] with an additional volume increase. Table 2 shows that the difference between the third and the first reading does not influence the volume variation of the cement pastes. The test values are lower than those indicated in the mentioned standard. 
The results of the mechanical properties and mortar durability with substitution equalize with time. Addition cement is unfavorable in their properties at short setting times in the marine environment [43].

\subsection{Properties in Hardened State}

\subsubsection{Flexural and Compressive Strength}

The resistance of a cement considers that of a normalized mortar mixed with siliceous sand, with a water/cement ratio equal to 0.5 [26]. The tests were carried out on three prismatic molds of $40 \times 40 \times 160 \mathrm{~mm}$, completed with mortar, according to the standard. In all the tests, the strengths for one year are considered, starting with the flexural strength. Compared with standard cement, all of the additions show lower values than that relative to the OPC: the lowest value coincides with $20 \%$ substitution. Flexural strength measurements are achieved in all substitutions, lower than those of the OPC, but almost equal, after the reaction year, when the substitution is $10 \%$ waste, while the $20 \%$ waste substitution remains with lower values in all times studied, as seen in Figure 3.

12

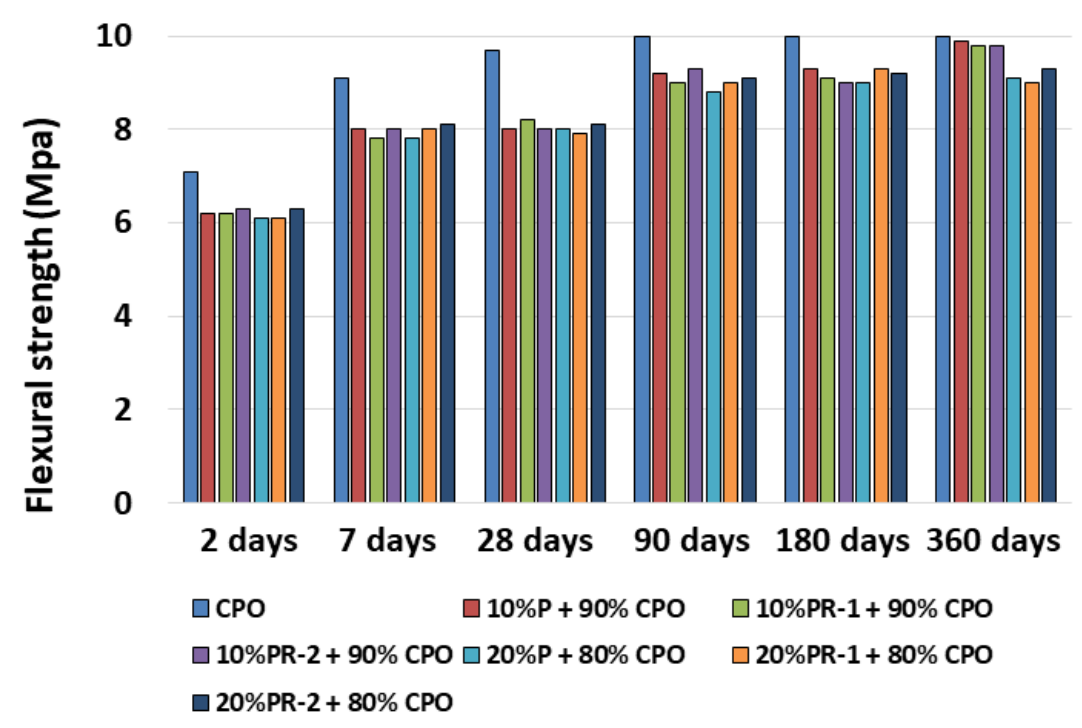

Figure 3. Variation of the flexural strength for all specimens.

The particle size of the system also influences the development of resistances-these being higher the greater the reaction surface provided by the cement.

The partial substitution of pozzolanic materials in the OPC generates a decrease in the resistance in the first curing ages, while in the long-term, they can reach (or even exceed) the strengths of the OPC. The hydrated calcium silicate $3 \mathrm{CaO} 2 \mathrm{SiO}_{2} \mathrm{H}_{2} \mathrm{O}(\mathrm{C}-\mathrm{S}-\mathrm{H}$ gels) in its different forms and structures, is the main responsible for cohesion and resistance. Consequently, an increase in said product due to the pozzolanic reaction causes a gain in mechanical resistance in the medium- and long-term.

The mortars to be obtained must be of the compression resistance class after setting $42.5 \mathrm{~N}$ (normal resistance) or $42.5 \mathrm{R}$ (high initial resistance), with initial resistance values after 2 days, higher or equal to $10 \mathrm{MPa}$ for $42.5 \mathrm{~N}$ and equal to or greater than $20 \mathrm{MPa}$ at $42.5 \mathrm{R}$; then, after 28 days, reach values equal to or greater than $42.5 \mathrm{MPa}$, in both classes [28].

Short-time compression values increase with the formation of amorphous C-S-H gels and when the concentration of portlandite decreases [44]. Setting time, mechanical strength, and shrinkage are related with higher mechanical strength, since it implies less shrinkage [45]. The elasticity modulus under compression increases as the percentage of cement substitution for siliceous materials is higher [40]. 
Amorphous materials generate a strength gain at an early age due to the filler effect, which is immediate and facilitates the acceleration of cement hydration during the first day. The maximum effect occurs between 7 and 14 days for replacement percentages between $5 \%$ and $30 \%$. After 14 days of curing, the strength gain is less [46].

The incorporation of granite wastes in mortars does not modify the logarithmic trend that links composition and curing time, regardless of the percentage of waste substitution ( $10 \%$ or $20 \%$ ) [47]. Figure 4 show the results when $10 \%$ waste is added: the compressive strength increases with time and, in all cases, exceeds the OPC value. However, there is a $20 \%$ waste substitution, and after 28 days of reaction, the trend changes and coincides with that proposed by Ramos et al. [17] in conventional mortars, and with results similar to those of Frías et al. [48] and Vardhan et al. [49], when studying sludge and calcareous materials, respectively, in the manufacturing of new cements. As shown in Figure 4, the highest values correspond to the PR-2 sample, although at the end of the time, the compressive strengths are equalized.

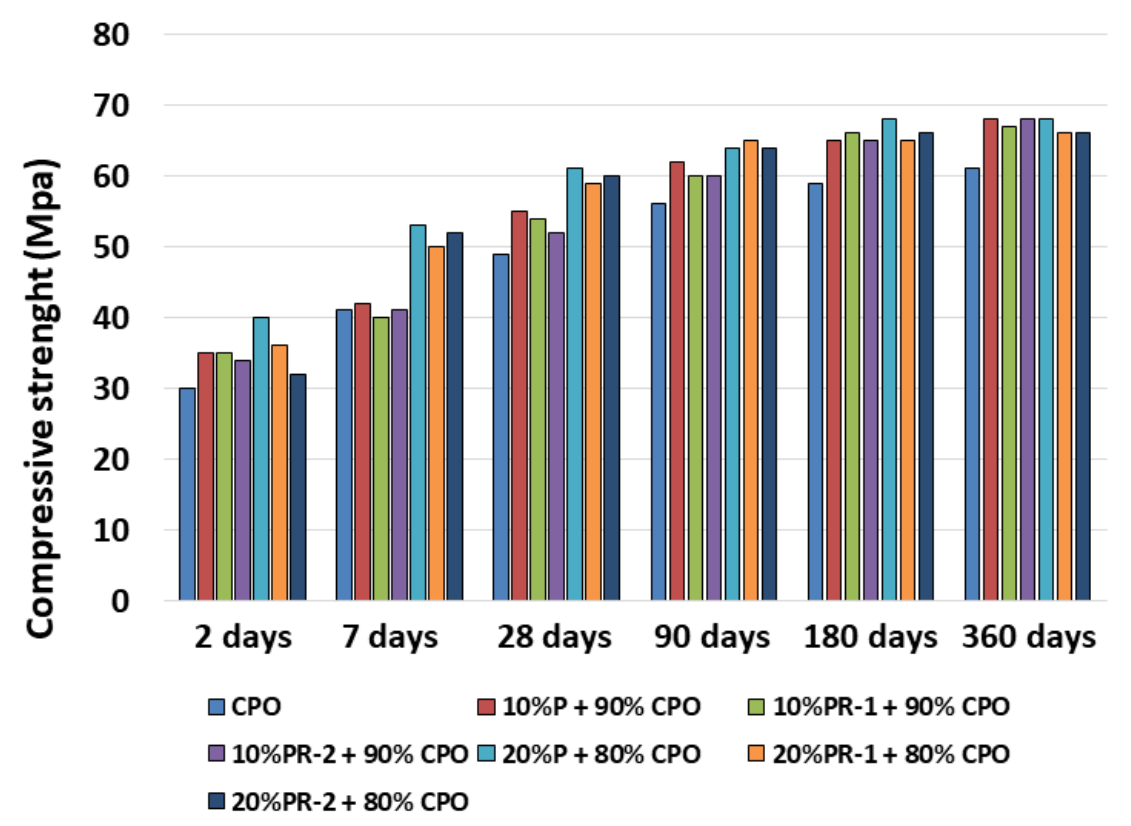

Figure 4. Variation of the compressive strength values for all studied samples.

Abd-Elmoaty [50] considers granite powder substitutions of different percentages ( $5 \%$ and $10 \%$ ). The optimal addition is $10 \%$, generating a positive effect on the tensile strength and without detecting changes in the chemical phases of the mixture with respect to the standard cement.

\subsubsection{Porosity}

Given that the mechanical resistance of cement-based materials is closely related to the porosity of the cementing matrix [36], the size, volume, and distribution of the pores in the specimens were determined. Computed tomography was performed (NIKON CT-Scanner XT-H-160 with Target of W, filter of $0.375 \mathrm{~mm}$ Cu with times of $708 \mathrm{~ms}$ per frame with a total of four frames, and the number of projections from 1100 to $155 \mathrm{kV}$ and $57 \mu \mathrm{A}$ ) to obtain images of cuts in the different internal structures and pore size of the systems. Ostrowski et al. [20] consider that substitutions of around 7\% waste improve the mechanical and elastic properties when different particle sizes are combined, avoiding homogeneity. In the same line, Pacheco Torgal and Castro-Gomes [19] express themselves by adding between 20 and $50 \%$ of granite powder to cement.

The largest number of pores in the mortars with addition corresponds to the small size at the initial moment of the hydration reaction of the PR-1 sample, decreasing markedly later. In Figure 5, the mentioned relationship with the particle size of the granite sawdust 
waste can be seen; which is smaller than in the OPC cement. Pores with greater volume are scarce in all reaction times and additions, except in $20 \%$ waste substitution, where there is a greater volume of pores, which then diminish after one year of reaction.

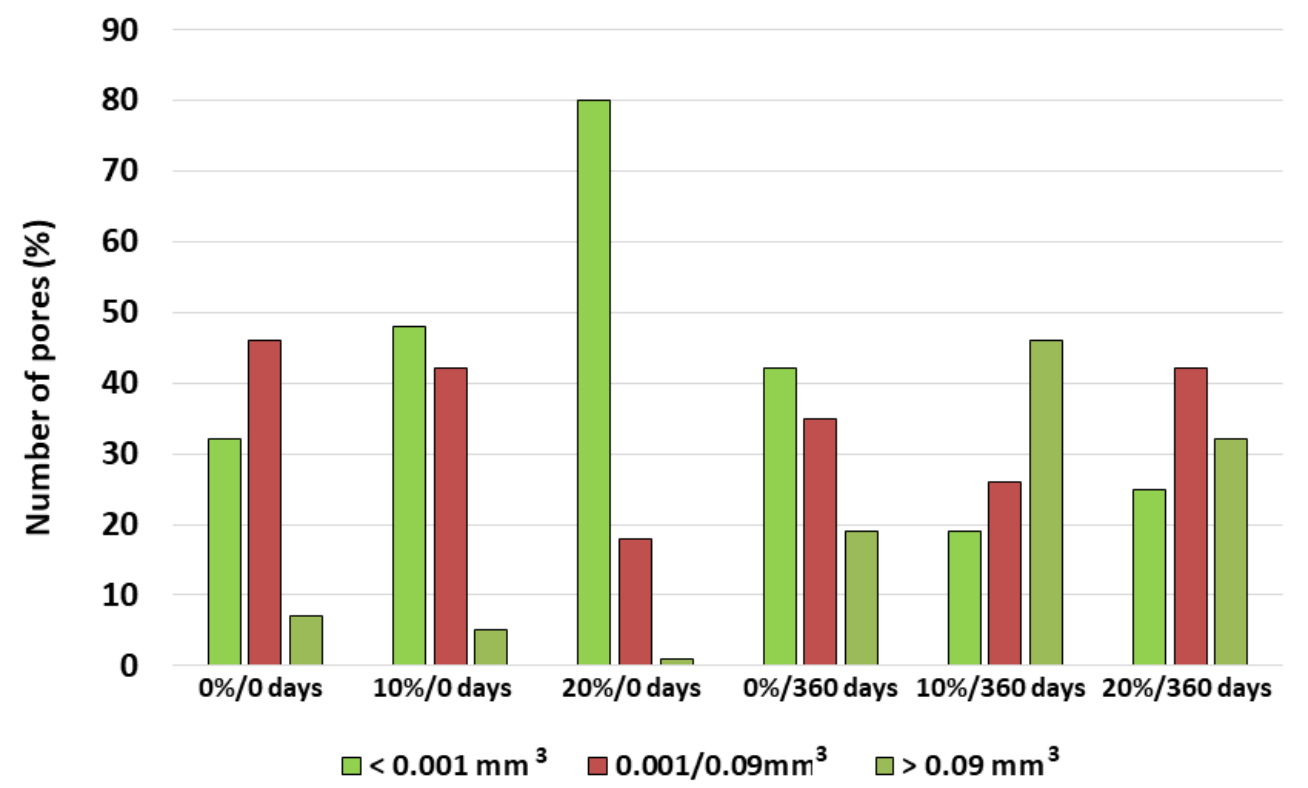

Figure 5. Macroporosity quantification (in \% of number of pores) grouped into three pore volume range $\left(>0.09 \mathrm{~mm}^{3}, 0.09 \mathrm{~mm}^{3}-0.001 \mathrm{~mm}^{3},<0.001 \mathrm{~mm}^{3}\right)$ for PR-1 sample.

The number of intermediate volume pores in the OPC is almost constant throughout the reaction time, perhaps with a slight decrease, per year, and, finally, pores of lower volume are the majority, remaining in the OPC throughout the time. Their number increases when the waste substitution is $10 \%$, a trend that is very markedly repeated for $20 \%$ waste substitution.

Total porosity and average pore size in the mortars with granite sawdust substitution after one year of curing are modified with regard to OPC, generating a decrease in the average porosity $\left(0.001\right.$ to $\left.0.09 \mathrm{~mm}^{3}\right)$ of mortars with $10 \%$ and $20 \%$ waste substitutions. The trend changes after one year when the substitution is $20 \%$.

The average pore size changes as the cement hydration process develops towards a smaller size in the case of low-value substitutions, with regard to the initial mortars [51], showing the importance of the pore diameter in relation to the volume total sample. For volume of pores, the most numerous are those greater than $0.09 \mathrm{~mm}^{3}$. These pores remain constant in number throughout the hydration reaction. Intermediate pores are almost non-existent; they decrease for a 10\% waste substitution per year, as shown in Figure 6.

Small pores are predominant in size in mortars with addition; their quantity decreases over time, unlike those of greater volume. The above observation is clearly detected from the electron microscope images studied in the mortars in Figure 7A, allowing us to appreciate the grain edges of the mortars without substitution. The grains are held together by $\mathrm{C}-\mathrm{S}-\mathrm{H}$ gels and ettringite fibbers, which give them a slightly porous appearance, as seen in Figure 7B.

Porosity is linked to the existence of C-S-H gels [52]. They are gels that change their morphology according to their degree of hydration, so that the needle growth naturally forms over time, accelerated by rapid drying - their growth being interrupted by slow drying [53]. Figure 8 allows this observation. C-S-H gels are materials highly sensitive to temperature and their apparent density increases with changes in thermal cure from $5^{\circ} \mathrm{C}$ to $50{ }^{\circ} \mathrm{C}$. Their increase means that gels take up less space, resulting in higher capillary porosity [54] that has a detrimental effect on mechanical properties and durability at high temperature [55]. C-S-H gels at the beginning of their formation are metastable and can evolve, slowly generating water and portlandite [56]. 


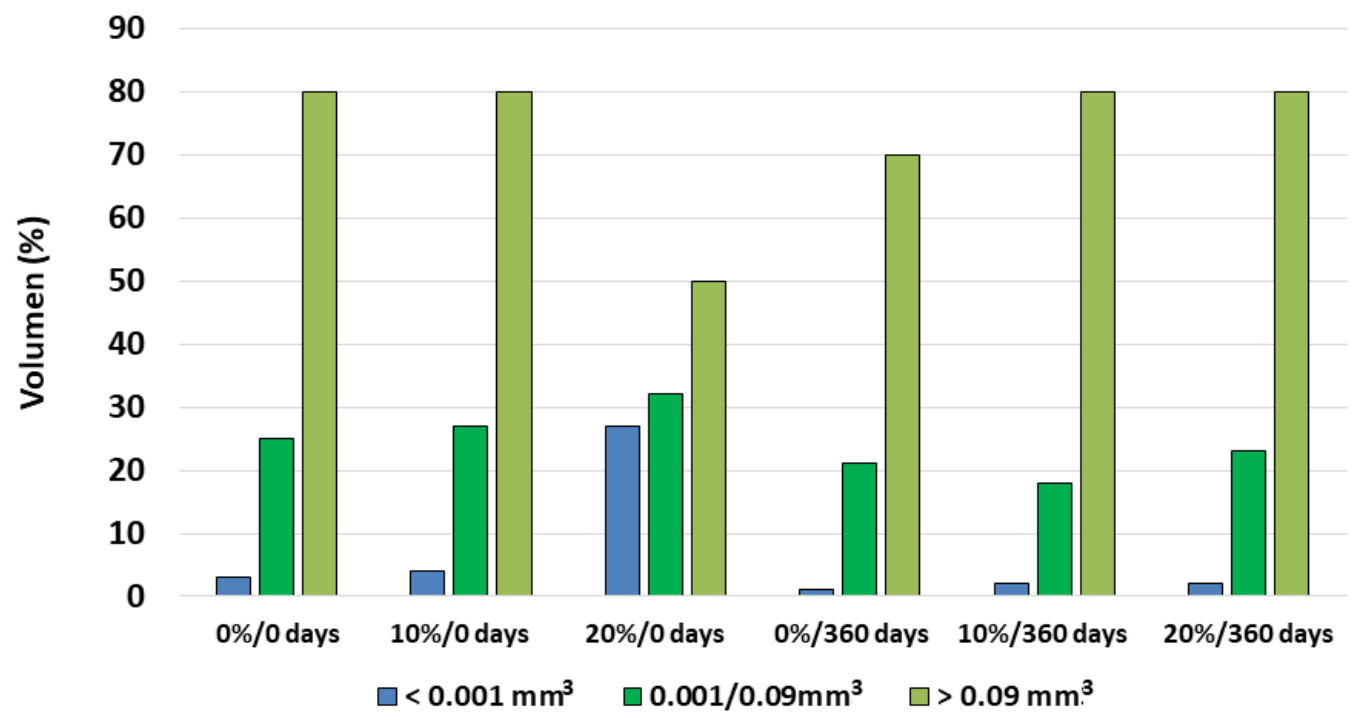

Figure 6. Macroporosity quantification (in \% of pore volume) grouped into three pore volume ranges $\left(>0.09 \mathrm{~mm}^{3},<0.09 \mathrm{~mm}^{3},>0.001 \mathrm{~mm}^{3},<0.001 \mathrm{~mm}^{3}\right)$ for PR-1 sample.
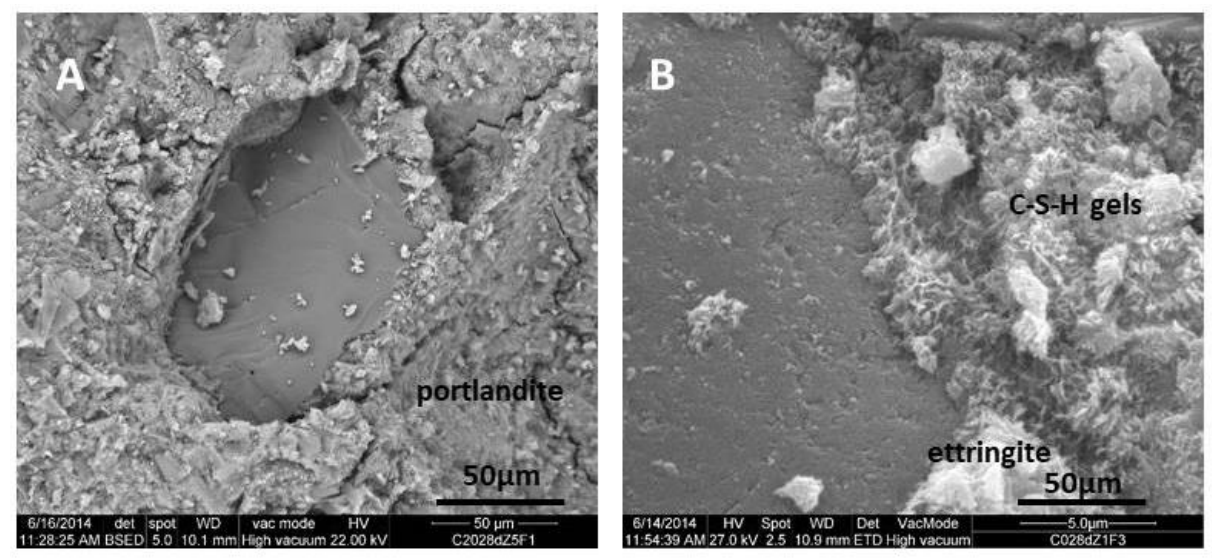

Figure 7. CPO sample without addition at one year of reaction. (A) Enlarged image of grain contact with portlandite. (B) Ettringite crystals with porous C-S-H gels.
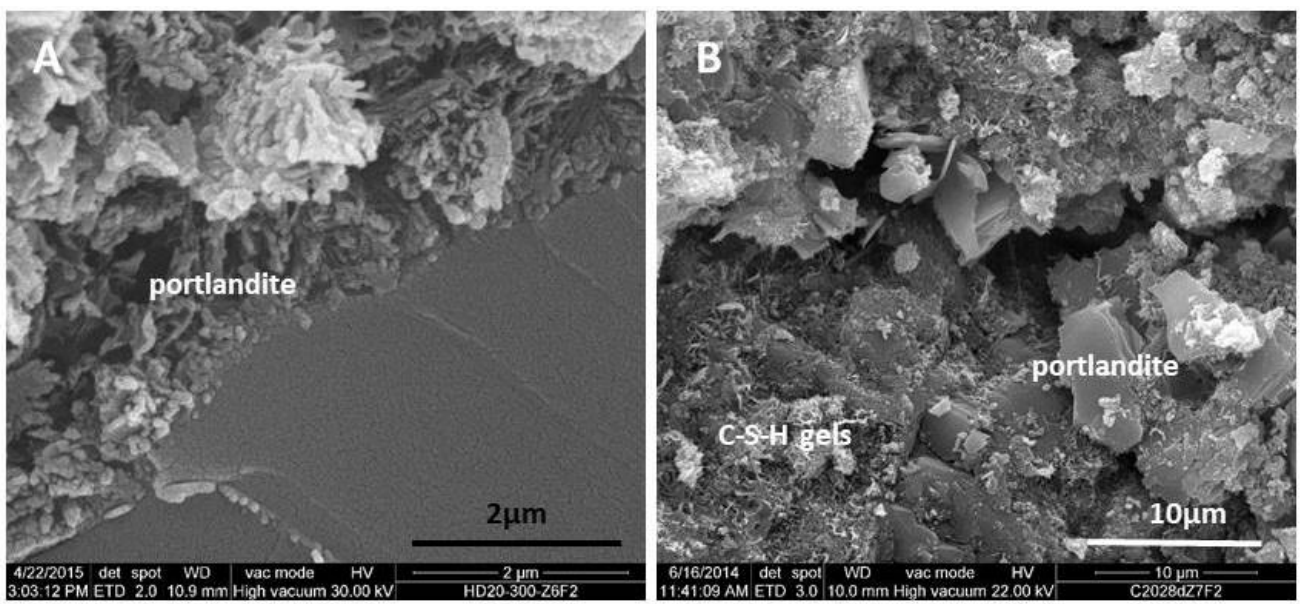

Figure 8. Mortar with 20\% substitution at one year of reaction. (A) Grain-to-grain contact with oriented portlandite sheets. (B) Aggregates have increased in size. 


\subsubsection{Durability in Gelifraction Processes}

Freeze/thaw processes are one of the main causes of degradation of mortar and concrete [57] in cold climate regions [58]. The durability of the systems in the gelling processes has been measured for twelve hours in order to ensure that, when the ice formed in the cooling cycle melts, it melts completely and goes to liquid state [33].

The speed of the ultrasonic wave velocity was measured in a TICO PROCEQ ultrasound meter with frequencies of $54 \mathrm{~Hz}$ and the relative dynamic modulus of elasticity was determined [34]. Compressive strength was determined according to UNE-EN 196-1 [26]. Porosity was measured by mercury intrusion with BET. The resistance to gelling was considered when the following occurred: (a) relative modulus of elasticity was equal to or less than $60^{\circ} \mathrm{C}$, and (b) breakage of the specimen with external cracking.

Each mortar type manufactured: (1) two $80 \times 80 \times 400 \mathrm{~mm}$ prisms to measure the relative dynamic modulus of elasticity by means of ultrasonic wave propagation and weight variation and, (2) twelve $40 \times 40 \times 160 \mathrm{~mm}$ prisms to evaluate compressive strength before each freeze/thaw cycle and after 28,62 , and 114 cycles.

The results obtained are presented in Figures 9 and 10 for mortars with $10 \%$ and 20\% waste substitution from PR-1 granite sawdust waste. The maximum number of freeze/thaw cycles in which the structure remained after testing two specimens has been considered as standard, according to the data mentioned in Table 3.

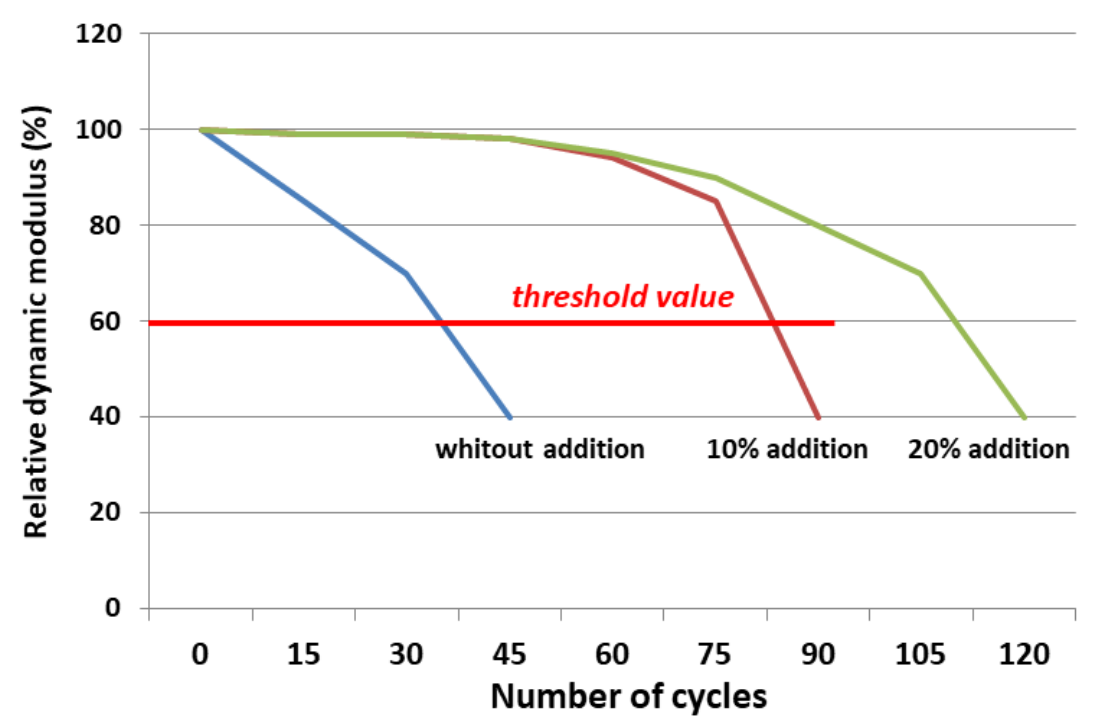

Figure 9. Variation of the relative dynamic module due to failure when reaching $60 \%$ failure.

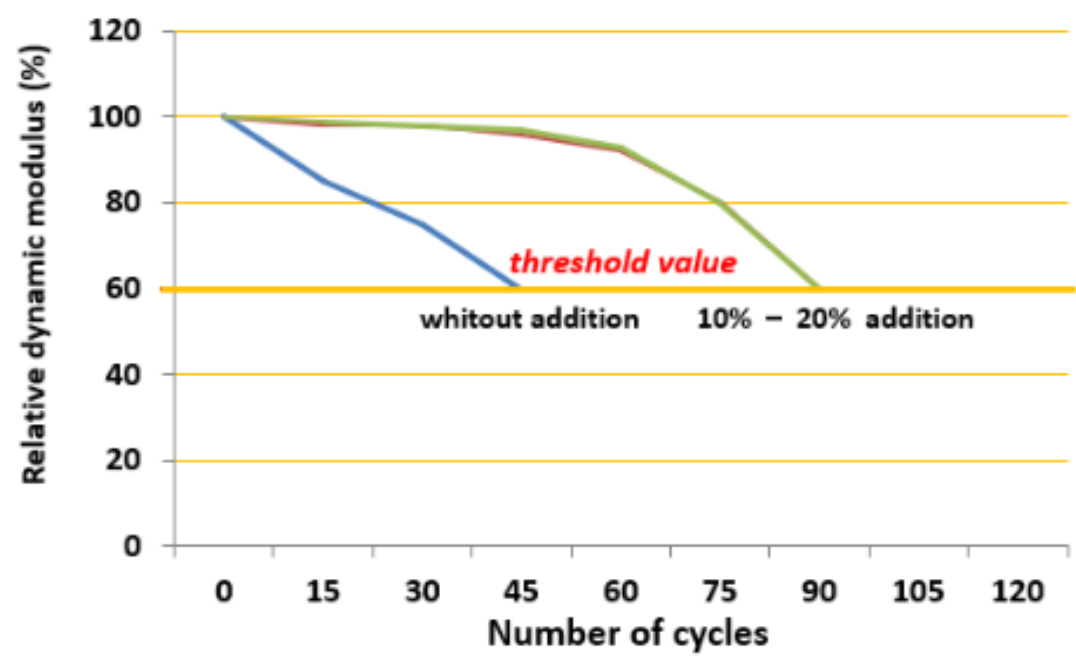

Figure 10. Variation of the relative dynamic modulus due to cracking failure. 
Table 3. Number of cycles before failure occurs.

\begin{tabular}{cccc}
\hline & Without Addition & $\mathbf{1 0} \%$ Addition & $\mathbf{2 0 \%}$ Addition \\
\hline crack failure & 30 & 64 & 82 \\
$60 \%$ threshold & 35 & 86 & 110 \\
mean & 32.5 & 75 & 95 \\
\hline
\end{tabular}

Mortars with substitutions have very similar behavior up to 45 cycles; a relevant fact, since the mortar without addition shows deterioration due to gradual failure, reaching the threshold value in those 45 cycles. In Figure 9, corresponding to $60 \%$ failure, it can be seen that the mortar with $20 \%$ addition is more resistant to gelling than $10 \%$ replacement.

Something similar happens in the figure for cracking failure. The parity of mortars with replacement, both $10 \%$ and $20 \%$, is different from that of mortar without addition and reaches longer times in terms of number of cycles. The porosity values obtained are provided in Table 4.

Table 4. Total porosity of mortars (\%) exposed to gelifraction cycles.

\begin{tabular}{cccc}
\hline Cycles (Number) & Without Addition & $\mathbf{1 0} \%$ Addition & $\mathbf{2 0} \%$ Addition \\
\hline 0 & 10.15 & 13.23 & 12.96 \\
64 & 17.12 & 15.32 & 11.53 \\
92 & 19.21 & 15.30 & 15.22 \\
\hline
\end{tabular}

Table 4 shows that the total porosity values are between $10 \%$ and $14 \%$, with values similar to those obtained by Pera et al. [59] for pozzolanic cements made from calcined paper sludge, which also coincide with those cited by Frías and Cabrera [60] in metakaolinbased pozzolans.

The greatest strengths of mortars made with additions are related to the size of the pores. When 65 cycles are reached, the mortars show a distribution in which a secondary peak appears between $1 \mu$ and $300 \mu$-that is, towards a smaller pore size. Mortar without addition has a larger pore size.

Compressive strength values in mortars with addition once again influence the best results when it comes to binary cements—-that is, with addition. Sabir [61] already carried out this evaluation with additions of silica fume and Girodet et al. [62] in metakaolin.

\section{Conclusions}

Three samples of ornamental stone sawmill granite sawdust have been studied. They were siliceous rocks with quartz, biotite, kaolinite, amorphous material, and feldspars (albite and orthoclase). The particle sizes were between $5 \mu \mathrm{m}$ and $9.5 \mu \mathrm{m}$.

Natural samples have been tested for pozzolanicity tests. After one year of cement reaction, and follow-up at 1, 7, 28, 90, 180, and 360 days, all of the samples showed pozzolanic activity, with higher values of pozzolanic activity for grey granite sawdust waste. This waste content was a large amorphous material concentration.

When $10 \%$ waste was added to the OPC, the same compounds were produced as if they were cement, without substitution, and coexisting with the initial minerals in the waste (quartz, feldspar, mica, kaolinite, and hematite). When $20 \%$ was added, the processes were similar to that mentioned for $10 \%$, in terms of the hydration products obtained, and those inherited from the initial composition. C-S-H gels and LDH compounds appeared in large quantities. In the samples with substitution, portlandite concentration decreased in medium times and remained in long.

Shortest setting times corresponded to the residue additions with the highest percentage related to the particle size and amorphous material present; therefore, it took the least time to set.

The shrinkage values that have been measured were directly proportional to time, with the smallest values for $20 \%$ substitution after one year, the percentage of addition did 
not influence the shrinkage, and all of the waste was equal in behavior. The volumetric stability showed a slight increase in the expansion of the pastes with an addition of $10 \%$, but the values obtained in the additions and samples were within the standard.

The flexural strength for all wastes and for all additions was less than the OPC. Lower results coincided with short cure times, but equalized over time. The compressive strength increased in all waste and substitutions, stabilizing in the year.

Total porosity and average size of the pores in the mortars with addition were modified with respect to the OPC. There was a decrease in porosity from 0.001 to $0.09-\mathrm{mm}^{3}$ of the mortars with substitutions of $10 \%$ and $20 \%$. The most abundant pore volume was greater than $0.09 \mathrm{~mm}^{3}$, keeping its number constant throughout the hydration reaction. Mediumsized pores were reduced in number, from $10 \%$ addition and with $20 \%$ addition; larger pores were almost non-existent.

Mortars made with $10 \%$ and $20 \%$ waste substitutions have a higher durability in terms of gelifraction processes, compared to mortars without addition.

Author Contributions: S.Y. formal analysis; C.G.-G.: validation; V.R.-P.: conceptualization; A.S.-L.: investigation. All authors have read and agreed to the published version of the manuscript.

Funding: This research received no external funding.

Acknowledgments: We thank Granitos Cardeñosa, Ávila (Spain) for the possibility of collecting samples at their facilities for this study.

Conflicts of Interest: The authors declare no conflict of interest.

\section{References}

1. Available online: www.Oficemen.com (accessed on 15 January 2021).

2. Miller, S.A.; John, V.M.; Pacca, S.A.; Horvath, A. Carbon dioxide reduction potential in the global cement industry by. Cem. Concr. Res. 2018, 114, 115-124. [CrossRef]

3. Klein, H.; Hoenig, V. Model calculations of the fuel energy requirement for the clinker burning process. Cem. Int. 2006, 4, 44-63.

4. Bauer, K.; Hoenig, V. Energy efficiency of cement plants. Cem. Int. 2010, 8, 148-152.

5. García, R.; Vigil, R.; Rodríguez, O.; Frías, M. Study of hydrated phases present in calcined paper sludge (metakaolinite)/saturated $\mathrm{CaO}$ dissolution system cured at $40^{\circ} \mathrm{C}$ and 28 days of reaction. Mater. Sci. Eng. 2010, 527, 3936-3941. [CrossRef]

6. Villar-Cociña, E.; Valencia Morales, E.; Santos, S.F.; Savastano, H.; Frías, M. Pozzolanic behavior of bamboo leaf ash: Characterization and determination of the kinetic parameters. Cem. Concr. Com. 2011, 33, 68-73. [CrossRef]

7. Goñi, S.; Frías, M.; Vegas, I.; García, R.; Vigil de la Villa, R. Quantitative correlations among textural characteristics of CSH gel and mechanical properties. Case of ternary Portland cements containing activated paper sludge and fly ash. Cem. Concr. Com. 2012, 34, 911-916. [CrossRef]

8. Frías, M.; Vigil de la Villa, R.; de Soto, I.; García, R.; Baloa, T. Influence of activated drinking-water treatment waste on binary cement-based composite behavior: Characterization and properties. Comp. B Eng. 2014, 60, 14-20. [CrossRef]

9. Uchima, J.S.; Restrepo, O.J.; Tobón, J.I. Pozzolanicity of the material obtained in the simultaneous calcination of biomass and kaolinitic clay. Constr. Build. Mater. 2015, 95, 414-420. [CrossRef]

10. Aprinati, E.; Shafigh, P.; Bahri, S.; Farahani, J.N. Supplementary cementitious materials origin from agricultural wastes-A review. Const. Build. Mater. 2015, 74, 176-187. [CrossRef]

11. García-Giménez, R.; Vigil de la Villa, R.; Frías, M. From coal-mining waste to construction material: A study of its mineral phases. Environ. Earth Sci. 2016, 75, 478-485. [CrossRef]

12. Cordeiro, G.C.; Kurtis, K.E. Effect of mechanical processing on sugar cane bagasse ash pozzolanicity. Cem. Concr. Res. 2017, 97, 41-49. [CrossRef]

13. Thomas, B.S.; Kumar, S.; Arel, H.S. Sustainable concrete containing palm oil fuel ash as a supplementary cementitious material—A review. Renew. Sustain. Energy Rev. 2017, 80, 550-561. [CrossRef]

14. Cavalcante, D.G.; dos Santos, M.G.; Filho, J.S.; Pereira, R. Influence of the levels of replacement of Portland cement by metakaolin and silica extracted from rice husk ash in the physical and mechanical characteristics of cement pastes. Cem. Concr. Res. 2018, 94, 296-306. [CrossRef]

15. Yagüe, S.; Sánchez, I.; Vigil de la Villa, R.; García-Giménez, R.; Zapardiel, A.; Frías, M. Coal-Mining Tailings as a Pozzolanic Material in Cements Industry. Minerals 2018, 8, 46. [CrossRef]

16. Schneider, M.; Romer, M.; Tschudin, M.; Bolio, H. Sustainable cement production-present and future. Cem. Concr. Res. 2011, 41, 642-650. [CrossRef]

17. Ramos, T.; Matos, A.; Schmidt, B.; Rio, J.; Sousa-Coutinho, J. Granitic quarry sludge waste in mortar: Effect on strength and durability. Constr. Build. Mater. 2013, 47, 1001-1009. [CrossRef] 
18. Yagüe García, S.; Gonzalez Gaya, C. Durability analysis of pozzolanic cements containing recycled track ballast: Sustainability under extreme environmental conditions. Constr. Build. Mater. 2020, 242, 117999. [CrossRef]

19. Pacheco Torgal, F.; Castro-Gomes, J. Influence of physical and geometrical properties of granite and limestone aggregates on the durability of a C20/25 strength class concrete. Constr. Build. Mater. 2006, 20, 1079-1088. [CrossRef]

20. Ostrowski, K.; Stefaniuk, D.; Sadowski, L.; Krzywinski, K.; Rozanska, M. Potential use of granite waste sourced from rock processing for the application as coarse aggregate in high-performance self-compacting concrete. Constr. Build. Mater. 2020, 238, 117-794. [CrossRef]

21. Kumar Sharma, N.; Kumar, P.; Kumar, S.; Skariah Thomas, B.; Chandra Gupta, S. Properties of concrete containing polished granite waste as partial substitution of coarse aggregate. Constr. Build. Mater. 2017, 151, 155-164. [CrossRef]

22. Kumar Gupta, L.; Kumar Vyas, A. Impact on mechanical properties of cement sand mortar containing waste granite powder. Constr. Build. Mater. 2018, 191, 155-164. [CrossRef]

23. Abukersh, S.; Fairfield, C. Recycled aggregate concrete produced with red granite dust as a partial cement replacement. Constr. Build. Mater. 2011, 25, 4088-4094. [CrossRef]

24. Mashaly, A.; Shalaby, B.; Rashwan, M. Performance of mortar and concrete incorporating granite sludge as cement replacement. Constr. Build. Mater. 2018, 169, 800-818. [CrossRef]

25. Jain, A.; Gupta, R.; Chaudary, S. Performance of self-compacting concrete comprising granite cutting waste as fine aggregat. Constr. Build. Mater. 2019, 221, 539-552. [CrossRef]

26. UNE-EN 196-1. Métodos de Ensayo de Cementos. Parte 1: Determinación de Resistencias; Asociación Española de Normalización y Certificación: Madrid, Spain, 2018.

27. UNE-EN 196-3. Métodos de Ensayo de Cementos. Parte 3: Determinación del Tiempo de Fraguado y de la Estabilidad de Volumen; Asociación Española de Normalización y Certificación: Madrid, Spain, 2017.

28. UNE-EN 197-1. Cemento. Parte Composición, Especificaciones y Criterios de Conformidad de los Cementos Comunes; Asociación Española de Normalización y Certificación: Madrid, Spain, 2011.

29. UNE-EN 196-5. Métodos de Ensayo de Cementos. Parte 5: Ensayo de Puzolanicidad para los Cementos Puzolánicos; Asociación Española de Normalización y Certificación: Madrid, Spain, 2011.

30. ASTM C489. Standard Test Method for Static Modulus of Elasticity and Poisson's Ratio of Concrete in Compression; ASTM INTERNATIONAL: West Conshohocken, PA, USA, 1964.

31. ASTM C512. Standard Test Method for Creep of Concrete in Compression; ASTM INTERNATIONAL: West Conshohocken, PA, USA, 2002.

32. ASTM C596. Standard Test Method for Drying Shrinkage of Mortar Containing Hydraulic Cement; ASTM INTERNATIONAL: West Conshohocken, PA, USA, 2018.

33. ASTM C666. Standard Test Method for Resistance of Concrete to Rapid Freezing and Thawing; ASTM INTERNATIONAL: West Conshohocken, PA, USA, 2015.

34. Zaharieva, R.; Buyle-Bodin, F.; Wirquin, E. Frost resistance of recycled aggregate concrete. Cem. Concr. Res. 2004, 34, 1927-1932. [CrossRef]

35. Basheer, L.; Cleland, D. Freeze-thaw resistance of concretes treated with pore liners. Constr. Build. Mater. 2006, 20, 990-998. [CrossRef]

36. Appa Rao, G. Investigations on the performance of silica fume incorporated cement pastes and mortars. Cem. Concr. Res. 2003, 33, 1765-1770.

37. Young, R. The Rietveld Method; International Union of Crystallography on Crystallography: Chester, UK, 1993 ; p. 312.

38. Yagüe, S.; González Gaya, C.; Rosales Prieto, V.; Sánchez Lite, A. Sustainable Ecocements: Chemical and Morphological Analysis of Granite Sawdust Waste as Pozzolan Material. Materials 2020, 13, 4941. [CrossRef] [PubMed]

39. Darweesh, H. Limestone as an accelerator and filler in limestone substituted alumina cement. Ceram. Int. 2004, 30, 145-150. [CrossRef]

40. Duan, P.; Yan, C.; Zhou, W. Effects of calcined layered double hydroxides on carbonation of concrete containing fly ash. Constr. Build. Mater. 2018, 160, 725-732. [CrossRef]

41. Özgür Bezgin, N. Climate effects on the shoulder width measurements of prestressed concrete high speed railway sleepers of ballasted tracks. Measurement 2015, 75, 201-209. [CrossRef]

42. Bonavetti, V.; Rahhal, V.; Irassar, E. Studies on the carboaluminate formation in limestone filler-blended cements. Cem. Concr. Res. 2001, 31, 853-859. [CrossRef]

43. Thomas, C.; Setién, J.; Polanco, J.; Alaejos, P.; Sánchez de Juan, M. Durability of recycled aggregate concrete. Constr. Build. Mater. 2013, 40, 1054-1065. [CrossRef]

44. Cassagnabère, F.; Mouret, M.; Escadeillas, G. Early hydration of clinker-slag-metakaolin combination in steam curing conditions, relation with mechanical properties. Cem. Concr. Res. 2009, 39, 1164-1173. [CrossRef]

45. Sern, L.; Cheah, C.; Ramli, M. The setting behavior, mechanical properties and drying shrinkage of ternary blended concrete containing granite quarry dust and processed steel slag aggregate. Constr. Build. Mater. 2019, 215, 447-461.

46. Wild, S.; Khabit, J. Portlandite consumption in metakaolin cement pastes and mortars. Cem. Concr. Res. 1997, 27, 137-146. [CrossRef]

47. Yagüe Garcia, S.; Gonzalez Gaya, C. Reusing Discarded Ballast Waste in Ecological Cements. Materials 2019, 12, 3887. [CrossRef] 
48. Frías, M.; Vigil, R.; García, R.; de Soto, I.; Medina, C.; Sánchez de Rojas, M.I. Scientific and technical aspects of blended cement matrices containing activated slate wastes. Cem. Concr. Com. 2014, 48, 19-25. [CrossRef]

49. Vardhan, K.; Goyal, S.; Siddique, R.; Singh, M. Mechanical properties and microstructural analysis of cement mortar incorporating marble poder as partial replacement building materials. Constr. Build. Mater. 2015, 96, 615-621. [CrossRef]

50. Abd Elmoaty, M. Mechanical properties and corrosion resistance of concrete modified with granite dust. Constr. Build. Mater. 2013, 47, 743-752. [CrossRef]

51. Zhang, L.; Qian, X.; Yu, C.; Fang, M.; Qian, K.; Lai, J. Influence of evaporation rate on pore size distribution, water loss, and early-age drying shrinkage of cement paste after the initial setting. Constr. Build. Mater. 2019, 226, 299-306. [CrossRef]

52. Liu, L.; Wang, X.; Chen, H.; Wan, C. Microstructure-based modelling of drying shrinkage and microcracking of cement paste at high relative humidity. Constr. Build. Mater. 2016, 126, 410-425. [CrossRef]

53. Fonseca, P.; Jennings, H. The effect of drying on early-age morphology of C-S-H as observed in environmental SEM. Cem. Concr. Res. 2010, 40, 1673-1680. [CrossRef]

54. Bullard, J.; Jennings, H.; Livingston, R.; Nonat, A.; Scherer, G.; Schweitzer, J.; Thomas, J. Mechanisms of cement hydration. Cem. Concr. Res. 2011, 41, 1208-1223. [CrossRef]

55. Gallucci, E.; Zhang, X.; Scrivener, K. Effect of temperature on the microstructure of calcium silicate hydrate (C-S-H). Cem. Concr. Res. 2013, 53, 185-195. [CrossRef]

56. Gartner, E.; Maruyama, I.; Chen, J. A new model for the C-S-H phase formed during the hydration of Portland cements. Cem. Concr. Res. 2017, 97, 95-106. [CrossRef]

57. Cao, J.; Chung, D. Damage evolution during freeze-thaw cycling of cement mortar, studied by electrical resistivity measurement. Cem. Concr. Res. 2002, 32, 1657-1661. [CrossRef]

58. Singh, S.; Nagar, R. Agrawal, Performance of granite cutting waste concrete under adverse exposure conditions. J. Clean. Prod. 2016, 12720, 172-182. [CrossRef]

59. Pera, J.; Ambroise, J.; Chabannet, M. Transformation of Wastes into Complementary Cementing Materials. Mater. Sci. 2001, 199, 459-476.

60. Frías, M.; Cabrera, J. Pore size distribution and degree of hydration of metakaolin-cement pastes. Cem. Concr. Res. 2000, 30, 561-569. [CrossRef]

61. Sabir, B.B. Mechanical properties and frost resistance of silica fume concrete. Cem. Conc. Com. 1997, 19, 285-294. [CrossRef]

62. Girodet, C.; Chabannet, M.; Bosé, J.; Pera, J. Influence of the type of cement in the freeze-thaw resistance of the mortar phase of concrete. In Proceedings of the International RILEM Workshop on the Frost Resistance of Concrete, Essen, Germany, 22-23 September 1997; pp. 31-40. 